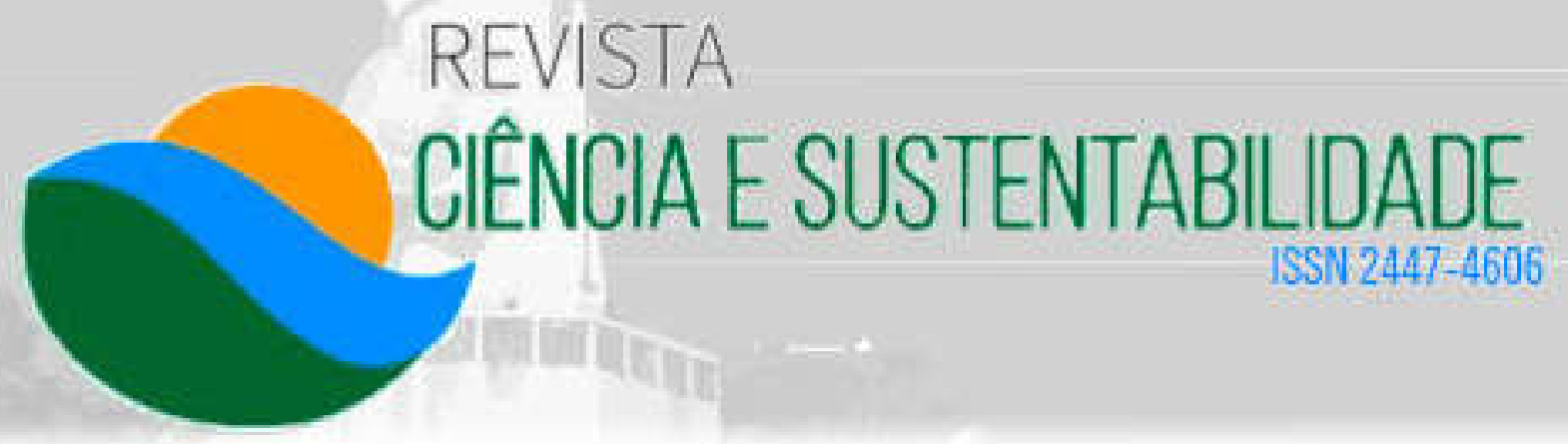

\title{
A RESPONSABILIDADE SOCIOAMBIENTAL NO SETOR DE CERÂMICA VERMELHA: UTILIZAÇÃO DO MÉTODO DELPHI PARA PROPOSIÇÃO DE UMA MATRIZ DE INDICADORES DE AVALIAÇÃO
}

Socio-environmental responsibility in the red ceramics sector: use of the delphi method for proposing a matrix of evaluation indicators

\section{Christiane Luci Bezerra Alves \\ Universidade Regional do Cariri (URCA) \\ chrisluci@gmail.com}

\section{Ahmad Saeed Khan \\ Universidade Federal do Ceará saeed@ufc.br}

\section{Patrícia Verônica Pinheiro} Sales Lima

Universidade Federal do Ceará pvpslima@gmail.com

\section{Valéria Feitosa Pinheiro \\ Universidade Regional do Cariri (URCA) \\ valeriafp@terra.com.br}

\section{Anderson da Silva Rodrigues Universidade Regional do Cariri (URCA) andersonrodrigues@urca.br}

\begin{abstract}
RESUMO
Esse ensaio tem como objetivo a proposição de uma matriz de indicadores de promoção da RSA no segmento de cerâmica vermelha. O setor em análise tem, reconhecidamente, alto impacto ambiental negativo; as principais fontes de matériaprima têm origem mineral (argila) e vegetal (lenha). A metodologia proposta consiste, a partir da literatura especializada do setor, trabalhar na construção de um conjunto de indicadores e dimensões de mensuração da RSA, utilizando, para isso, a metodologia Delphi, que se baseia na construção de um consenso sobre importância relativa dos indicadores, a partir da contribuição de um conjunto de especialistas na temática.
\end{abstract}

Palavras-chave:Responsabilidade Socioambiental (RSA). Cerâmica Vermelha. Método Delphi.

\section{ABSTRACT}

This essay aims to propose a matrix of RSA promotion indicators in the red ceramic segment. The sector under analysis has admittedly high negative environmental impact; the main sources of raw material are mineral (clay) and vegetal (firewood). The proposed methodology consists, 
based on the specialized literature of the sector, to work on the construction of a set of indicators and measurement dimensions of the RSA, using the Delphi methodology, which is based on the construction of a consensus on relative importance of the indicators, fron the contribution of a set of specialists in the subject.

Keywords: Socio and environmental responsibility. red ceramic. Delphi method. 


\section{INTRODUÇÃO}

O cenário competitivo e globalizado das últimas décadas do século $X X$ demanda respostas da empresa global, que passa a incorporar novos critérios de competitividade. Em tal contexto, as ações sociais empresariais, historicamente ligadas a intervenções assistenciais e filantrópicas, começam a modificar seu perfil pontual, heterogêneo e dependente da coordenação estatal, em busca de um novo padrão que considere relações éticas e responsáveis que digam respeito à sociedade e ao meio ambiente. A responsabilidade socioambiental (RSA) passa a se constituir como um estratégico instrumento de gestão para a manutenção da competitividade e sobrevivência no campo empresarial.

É inegável que o tema da RSA tenha sido foco central de recentes discussões em diferentes aspectos; apesar de grande avanço na literatura, os custos ambiental e social não têm sido historicamente internalizados e principalmente custos sociais atrelados à degradação ambiental são muitas vezes tratados como externalidades. Assim, as abordagens focadas na questão ambiental parecem ainda se constituir num campo para inúmeras investigações.

Esse ensaio tem como objetivo a proposição de uma matriz de indicadores de promoção da RSA no segmento de cerâmica vermelha. O setor de análise tem alto impacto ambiental negativo. As principais fontes de matéria-prima têm origem mineral (argila) e vegetal (lenha). A extração da argila promove desmatamento acelerado, degradação das margens de rios e riachos e consequente degradação de matas ciliares; o consumo da lenha contribui para a devastação das matas nativas e a queima de produtos gera emissão em quantidades apreciáveis de certos componentes gasosos como: monóxido de carbono (CO), óxidos de nitrogênio (NOx), óxidos de enxofre (SOx), amônia (NH3) e metano (CH4). O caráter invasivo e os impasses impostos ao meio ambiente reconfiguram paisagens e constituem ameaças à fauna presente nas regiões de exploração da 
atividade. Grande parte do processo de produção tem efeito sobre o meioambiente, equipamentos, ferramentas e saúde humana (BEZERRA; VIANA; FARIA JR., 2001; LINARD, 2011; SOUSA et al, 2006).

Além desta introdução, este artigo apresenta a seguinte estrutura: na seção 2, são discutidos os fundamentos histórico-conceituais da Responsabilidade Socioambiental. Na seção 3, abordam-se os aspectos metodológicos da pesquisa e da construção do IRSA. Na seção 4, são discutidos os resultados obtidos e, por fim, a quinta seção tece algumas considerações finais da pesquisa.

\section{EM BUSCA DE UM CONCEITO PARA A RSA}

A supremacia da lógica da "sociedade de mercado" nos modelos de desenvolvimento econômico, ancorados por uma racionalidade instrumental eminentemente econômica, confere à empresa o papel de núcleo fundamental para o atendimento de necessidades, visando a um processo de acumulação. Nesse entendimento, a empresa tem uma responsabilidade única, na qual seus recursos humanos, físicos e tecnológicos devem estar direcionados para a maximização de lucros em benefício de seus acionistas (FRIEDMAN, 1984). É dentro dessa perspectiva que um conjunto de contribuições rumo à constituição de uma matriz conceitual para a RSA compreende a mesma inserida nas preocupações ideológico-estruturantes sobre a manutenção de um sistema social e econômico em seus princípios fundamentais de livre iniciativa e concorrência, intervenção do Estado na economia e oposições ideológicas ao próprio regime de produção e acumulação capitalista (BOWEN, 1957; ODELL, 1974; BLAU E SCOTT; 1977; FRIEDMAN 1984). Nesse vetor de análise, os mercados não podem e não devem ser o campo de concepção e realização de projetos sociais 
e o objetivo de voltar a produção material à satisfação imediata e explícita de necessidades sociais não pode ser atingido ${ }^{1}$ (ABRAMOVAY, 2009, p.340).

A partir dos anos 1970, um novo vetor de contribuições ganha espaço em novas discussões no campo acadêmico e político-institucional e as ações concretas de promoção da RSA no ambiente corporativo avançam, tendo como 'pano de fundo' o contexto de redefinição de paradigmas de regulação e acumulação globais, reformulação de modelos e estratégias de promoção do desenvolvimento, característico dos anos 1970, acirramento de processo de globalização e redefinição dos critérios de competitividade, que se aprofundam a partir da década de 1980.

Nos anos 1970, no âmbito das discussões de uma nova perspectiva de desenvolvimento, na qual o avanço da sustentabilidade nas práticas sociais é requerido como princípio que reja quaisquer relações entre indivíduos, organizações sociais, empresas ou Estado, os modelos de gestão que privilegiem apenas critérios interorganizacionais começam a ser questionados.

Embora a função social das empresas tenha sido largamente tratada como tema de estudo ao longo dos anos 1960 e 1970, nas duas décadas que se seguem, a busca pela legitimidade social de sua atuação passa a fazer parte dos planos de negócios da dinâmica da organização empresarial. Em consonância, demanda-se a intervenção do Estado na montagem de um aparato legal normativo que corrija e imponha às empresas o "ônus das externalidades, isto é, dos efeitos socialmente indesejáveis de seus atos" na busca pela maximização do lucro, na manutenção do sistema de preços e lógica do sistema capitalista (ABRAMOVAY, 2009, p.337).

\footnotetext{
1 Esse argumento permanece vigoroso, mesmo quando já se percebe em parte, nas obras de alguns autores, que é necessário se considerar pela empresa o conjunto de suas relações internas e externas com as diversas forças sociais envolvidas no seu campo de atuação.
} 
O reconhecimento de uma crise ambiental, que aponta limites estruturais ao modo de acumulação vigente, insere as consequências ambientais no rol das externalidades advindas da economia de mercado e consequentemente da atuação da empresa. Nesse sentido, aumenta-se, progressivamente, o peso que ações ambientalmente responsáveis assumem na responsabilidade corporativa. Para Tachizawa (2006, p. 23), a transformação e a influência ecológica nos negócios se fazem sentir de maneira crescente e com efeitos econômicos cada vez mais profundos. Veja-se: "As organizações que tomarem decisões estratégicas integradas à questão ambiental e ecológica conseguirão significativas vantagens competitivas, quando não, redução de custos e incremento nos lucros a médio e longo prazos".

Nesse sentido, o Instituto Ethos considera que a preocupação ambiental:

[..] é talvez a pedra-fundamental da discussão hoje em prática sobre o direcionamento do processo produtivo para a gestão responsável dos recursos, e não apenas para a geração de riqueza e consumo. Com diversos exemplos em todo o mundo, é possível afirmar que a evolução dos processos da iniciativa privada em relação à preservação de recursos naturais gera resultados mais favoráveis não somente para a sociedade e para as gerações futuras, mas para as próprias companhias, inclusive com ganhos financeiros (ETHOS, 2013).

O cenário mais competitivo e globalizado, característico dos anos 1990, marcado por intensa integração dos mercados financeiro, comercial e produtivo, demanda respostas da empresa global, que passa a incorporar novos critérios de competitividade. Desta forma, a responsabilidade social empresarial passa assim pela compreensão do modelo político-econômico instaurado a partir do processo de globalização, pelos problemas sociais estruturais decorrentes, pela necessidade da reforma do Estado e pelas pressões cada vez mais frequentes da sociedade civil (RICO, 2004, p. 75).

Como parte dessa dinâmica, demanda-se uma mudança na cultura organizacional, na qual a empresa é chamada a tornar-se agente ativo do 


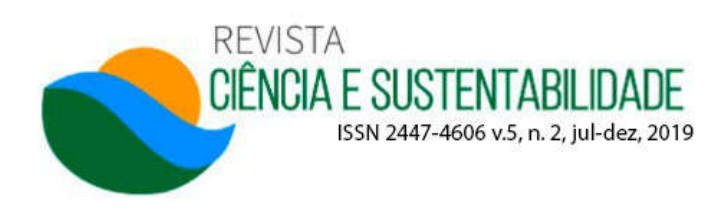

processo de construção de um modelo de sustentabilidade. Para Borger (2013, p.1), então:

O modelo da sustentabilidade é uma nova forma de fazer negócios, que tem como pressuposto o novo papel da empresa na sociedade. Sustentabilidade e responsabilidade social trazem para o modelo de negócios a perspectiva de longo prazo, a inclusão sistemática da visão e das demandas das partes interessadas, e a transição para um modelo em que os princípios, a ética e a transparência precedem a implementação de processos, produtos e serviços.

Sob tal orientação, a responsabilidade social é identificada por Ashley et al. (2002, p. 6) como o compromisso que uma organização deve ter para com a sociedade, "expresso por meio de atos e atitudes que afetam positivamente, de modo mais amplo, ou alguma comunidade, de modo específico, agindo proativamente no que tange a seu papel específico na sociedade e sua prestação de contas para com ela".

Para Melo Neto e Froes (2001), a responsabilidade social consiste em decisão de participar mais diretamente das ações comunitárias na região em que está presente e minorar possíveis danos ambientais decorrentes do tipo de atividade que exerce; busca estimular o desenvolvimento do cidadão e fomentar a cidadania individual e coletiva. Assim, ao deixar de cumprir suas obrigações sociais em relação aos seus empregados, acionistas, consumidores, parceiros e comunidade, a empresa perde o seu capital de responsabilidade social, ou seja, perde a sua credibilidade.

Enfatiza-se, aqui, a maior amplitude do conceito de responsabilidade social empresarial proposto pelo Instituto Ethos, definido como:

A forma de gestão que se define pela relação ética e transparente da empresa com todos os públicos com os quais ela se relaciona e pelo estabelecimento de metas empresariais compatíveis com o desenvolvimento sustentável da sociedade, preservando recursos ambientais e culturais para futuras gerações, respeitando a diversidade e a redução das desigualdades sociais (ETHOS, 2003a, p. 37). 


\section{PROCEDIMENTOS METODOLÓGICOS}

\subsection{MÉTODOS E TÉCNICAS}

A metodologia proposta consiste, a partir da literatura especializada do setor, trabalhar na construção de um conjunto de indicadores e dimensões de mensuração da RSA, utilizando, para isso, a metodologia Delphi, que se baseia na construção de um consenso sobre importância relativa dos indicadores, a partir da contribuição de um conjunto de especialistas na temática.

\subsubsection{Método Delphi}

O Método Delphi propõe uma análise qualitativa exploratória e consiste num exercício de comunicação em grupo entre diversos especialistas em determinado assunto (ADLER; ZIGLIO, 1996). Para Skulmoski, Hartman e Krahn (2007), trata-se de um método para decisão em grupo que coleta e refina julgamentos anônimos de especialistas, usando uma série de questionários e técnicas de análise interligados com feedback, baseado em um processo interativo.

A ideia é a de que especialistas interagem no anonimato, através de uma mediação, trocando informações repetidamente, de forma que se chegue o mais próximo de um consenso, ou uma abordagem considerada satisfatória pelo grupo. Ao ter acesso a um sumário anônimo das estimativas de cada especialista, ou ao resumo das discussões ao longo das rodadas, os especialistas também ampliam seu conjunto de informações, revisam e reconstroem conceitos. Assim, entendese que "o consenso coletivo, bem definido e parametrizado, é mais eficiente e completo que ideias individuais, aproveitando toda a sinergia do grupo de 
discussão, estabelecendo quais os focos mais importantes para a abordagem inicial" (PAULINO, 2010, p. 1).

Baseia-se em seis pilares fundamentais, a saber: anonimato; uso de especialistas; aplicação de rodadas interativas, com feedback; flexibilidade e busca por um consenso. São utilizados basicamente para a estruturação de conceitos e previsões de futuro (SÁFADI, 2001), mas a literatura também reconhece suas limitações. As vantagens e desvantagens do método estão sistematizadas no quadro 1.

Segundo De Carli, Delamaro e Salomon (2010, p. 553), esse método se aplica como instrumento de pesquisa quando "não existe completo conhecimento sobre um problema ou fenômeno, e funciona especialmente bem quando o objetivo é melhorar o entendimento de problemas, oportunidades, soluções, ou para desenvolver previsões".

Quadro 1 - Pilares fundamentais do Método Delphi - Vantagens e Desvantagens

\begin{tabular}{|c|c|c|}
\hline Pilares & Vantagens & Desvantagens \\
\hline Anonimato & $\begin{array}{l}\text { - O anonimato quebra barreiras à } \\
\text { comunicação e garante igualdade de } \\
\text { expressão de ideias, dificultando que se } \\
\text { forme um groupthink. Ou seja, diminui } \\
\text { efeitos restritivos da dinâmica de grupo, } \\
\text { como capacidade de persuasão de } \\
\text { determinados participantes. } \\
\text { - Também garante que a interatividade } \\
\text { ocorra com maior espontaneidade. } \\
\text { - Permite a participantes que não se } \\
\text { conhecem desenvolverem um projeto } \\
\text { comum. }\end{array}$ & \\
\hline Feedback & $\begin{array}{l}\text { - Possibilidade de conhecer novas } \\
\text { argumentações e rever posições para } \\
\text { construção de novos conceitos. }\end{array}$ & $\begin{array}{l}\text { - As rodadas sínteses dependem } \\
\text { fortemente do mediador, que } \\
\text { pode, por exemplo, excluir } \\
\text { pontos de discordância. }\end{array}$ \\
\hline
\end{tabular}




\begin{tabular}{|c|c|c|}
\hline Flexibilidade & $\begin{array}{l}\text { - Facilidade na comunicação dos } \\
\text { participantes. } \\
\text { - Evita-se a dispersão dos participantes } \\
\text { do painel. } \\
\text { - Agilidade para o feedback. }\end{array}$ & $\begin{array}{l}\text { - Como a comunicação é indireta, } \\
\text { novamenter depende-se } \\
\text { fortemente do compartilhamento } \\
\text { de informações do mediador. }\end{array}$ \\
\hline Interatividade & $\begin{array}{l}\text { - As rodadas interativas encorajam os } \\
\text { especialistas a revisarem, } \\
\text { constantemente, suas estimativas, num } \\
\text { processo de aprendizado recíproco } \\
\text { (possibilidade de revisão de visões } \\
\text { individuais). } \\
\text { - O compartilhamento constante das } \\
\text { respostas faz com que, na } \\
\text { interatividade, fuja-se de uma } \\
\text { conjuntura hierárquica. }\end{array}$ & $\begin{array}{l}\text { - A objetividade exigida pela } \\
\text { interatividade e feedback, por } \\
\text { exemplo, contraria o benefício de } \\
\text { obter respostas mais elaboradas } \\
\text { e fundamentadas. }\end{array}$ \\
\hline $\begin{array}{l}\text { Uso de } \\
\text { especialistas }\end{array}$ & $\begin{array}{l}\text { - Volume maior de informações } \\
\text { disponíveis. } \\
\text { - Construído a partir de uma } \\
\text { heterogeneidade de especialistas, } \\
\text { escolhidos em suas diferentes } \\
\text { experiências, o consenso perseguido } \\
\text { tende a ser mais robusto. }\end{array}$ & $\begin{array}{l}\text { - Dificuldade na seleção dos } \\
\text { respondentes e a excessiva } \\
\text { dependência dos resultados na } \\
\text { escolha dos especialistas. }\end{array}$ \\
\hline Consenso & $\begin{array}{l}\text { - Eficiência coletiva melhor que } \\
\text { contribuições individuais. }\end{array}$ & $\begin{array}{l}\text { - Uma possível exclusão de } \\
\text { determinados pontos pode } \\
\text { conduzir à formação de um falso } \\
\text { consenso. } \\
\text { - Consensos artificiais também } \\
\text { podem surgir se houver baixa } \\
\text { heterogeneidade do grupo } \\
\text { (consenso por pouca } \\
\text { diversidade). }\end{array}$ \\
\hline
\end{tabular}

Fonte: Adaptado a partir de Oliveira, Costa e Wille (2008) e Giovinazzo (2001).

Oliveira, Costa e Wille (2008) atentam para o fato de se utilizar o Delphi quando não são requeridas habilidades matemáticas ou estatísticas sofisticadas, diante da ausência de dados históricos sobre o problema pesquisado ou pouca disponibilidade de dados estatísticos, típicos de pesquisas exploratórias e, ainda, na presença de rupturas tecnológicas, econômicas, sociais ou políticas. Wright e Giovinazzo (2000) ratificam a utilização do método quando existe a necessidade de abordagem interdisciplinar para determinado problema de pesquisa. 


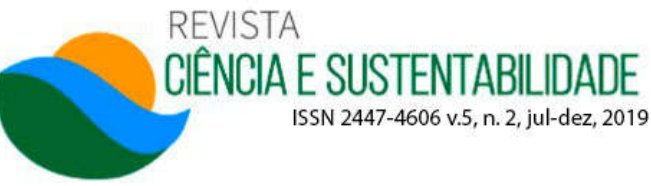

Em termos de operacionalização, os especialistas recebem um questionário respondendo-o individualmente, usualmente com respostas quantitativas apoiadas por justificativas e informações qualitativas. As proposições são apresentadas aos participantes, para que estas sejam ordenadas mediante um critério preestabelecido. Na sequência, conforme sistematiza Giovinazzo (2001, p.2) (Figura 1):

As respostas das questões quantitativas são tabuladas, recebendo um tratamento estatístico simples definindo-se a mediana e os quartis, e os resultados são devolvidos aos participantes na rodada seguinte. Quando há justificativas e opiniões qualitativas associadas a previsões quantitativas, a coordenação busca relacionar os argumentos às projeções quantitativas correspondentes.

A cada nova rodada as perguntas são repetidas, e os participantes devem reavaliar suas respostas à luz das respostas numéricas e das justificativas dadas pelos demais respondentes na rodada anterior. São solicitadas novas previsões com justificativas, particularmente se estas previsões divergirem das respostas centrais do grupo. Esse processo é repetido por sucessivas rodadas do questionário até que a divergência de opiniões entre especialistas tenha se reduzido a um nível satisfatório, e a resposta da última rodada é considerada como a previsão do grupo. 
Figura 1 - Sequência de execução de pesquisa Delphi

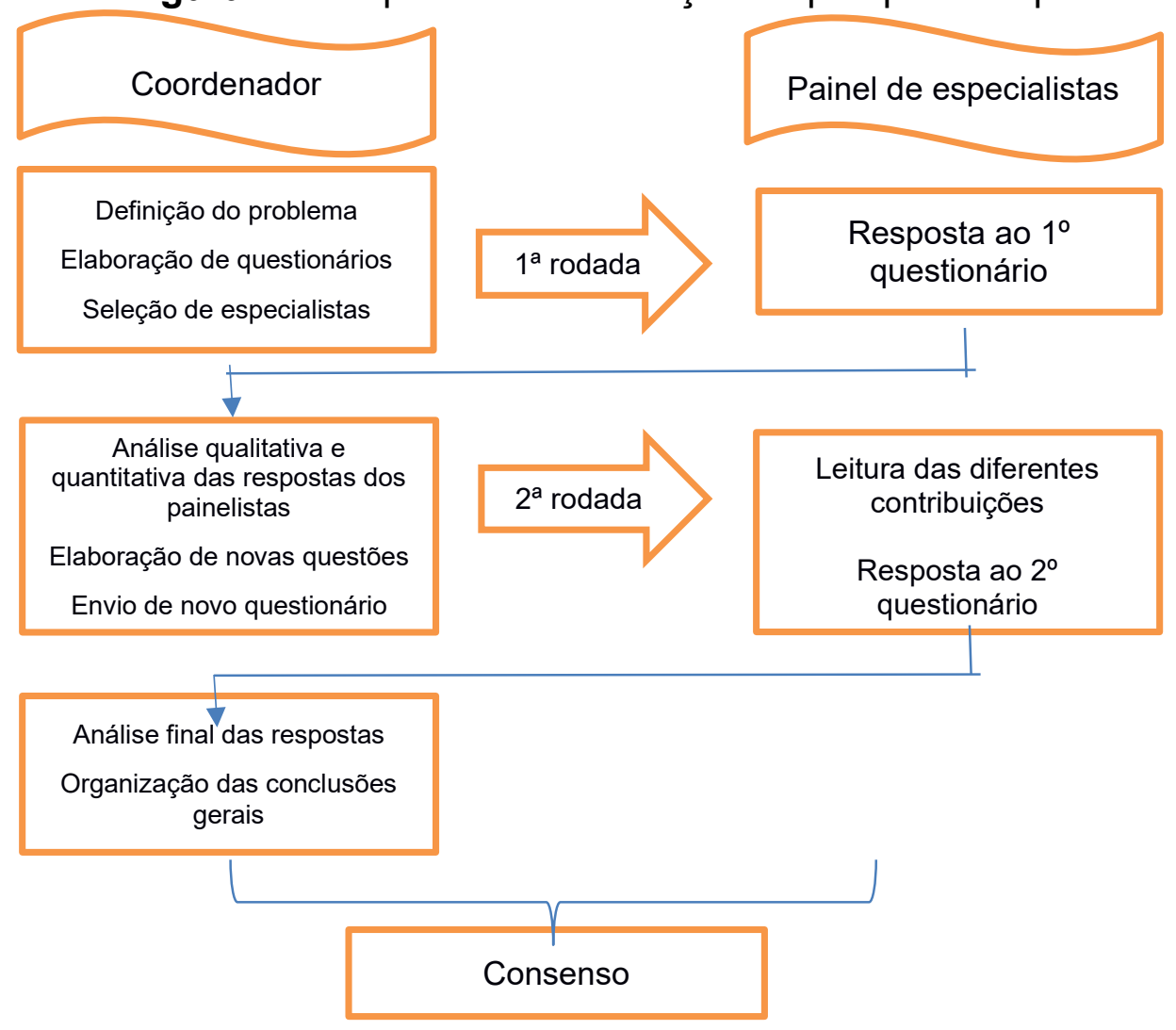

Fonte: Adaptado de Esperon et al. (2004).

Ressalta-se que não existe consenso na literatura sobre o número de especialistas a ser consultado. Nesse sentido, Giovinazzo (2001, p.8) chama atenção que o método:

[..] não pretende fazer um levantamento estatisticamente representativo da opinião de um determinado grupo amostrado, consistindo de uma consulta a um grupo limitado e seleto de especialistas, que através da sua capacidade de raciocínio lógico, da sua experiência e da troca objetiva de informações procura chegar a opiniões conjuntas sobre as questões propostas.

Sobre a sequência de rodadas, conforme Cândido et al. (2007, p. 162), "embora o número de rodadas possa ser ilimitado, deve-se evitar o excesso para 
não causar desinteresse na participação. É recomendado que o número de rodadas não exceda a quatro".

No processo de elaboração das questões, Cândido et al. (2007) destacam, ainda, que não se utilize, na sua estrutura, mais de um questionamento, a fim de evitar respostas inconsistentes e que se garanta a exclusão de perguntas com duplo sentido para evitar ambiguidades ou respostas subjetivas por parte dos respondentes.

\section{RESULTADOS E DISCUSSÕES}

Um questionário foi inicialmente proposto e aplicado junto a um painel de especialistas no tema RSA e da gestão ambiental, além de conhecedores do setor em questão, buscando não apenas construir um consenso sobre a importância relativa dos indicadores, mas contribuir para a construção da matriz de indicadores de promoção da RSA, com a inclusão de indicadores sugeridos no processo Delphi.

O painel de especialistas envolveu: professores e pesquisadores de diferentes instituições de ensino; órgãos ambientais, como SEMACE, Secretaria Municipal do Meio Ambiente - Crato, FLONA, ICMbio, Geopark Araripe; instituições diversas como ETENE/Banco do Nordeste, SEBRAE, IBGE e estudiosos e pesquisadores de ONG de atuação ambiental.

Conforme sugerido, o julgamento de especialistas foi apreendido por meio da escala de opiniões em cinco pontos, permitindo-lhes observações e sugestões de novos indicadores. Após a primeira rodada, sendo ali já constatado importante grau de concordância entre os especialistas, escolheu-se como critério para definir a importância do indicador, a nota modal. Concluídas três rodadas de consultas a especialistas e constatando-se que a ordem estabelecida possuía 
forte respaldo na literatura pesquisada, foram propostas as seguintes dimensões de promoção da RSA e seus respectivos indicadores.

O grau de importância atribuído à cada indicador, baseado na escala likert, encontra-se indicado também no quadro 1, e pode ser utilizado em metodologias de mensuração, como na construção de índices sintéticos de mensuração.

\subsection{DIMENSÕES PROPOSTAS PARA A RSA}

A multiplicidade de abordagens e estratégias de promoção da responsabilidade socioambiental remete à constante necessidade de mensuração da mesma, o que passa a ser utilizado crescentemente como parte da gestão estratégica das corporações, permitindo à própria empresa o acompanhamento e consolidação de suas ações socioambientais. Para isso, recorre-se a mecanismos de mensuração através da construção de indicadores, definidos como "ferramentas constituídas por uma ou mais variáveis que, associadas através de diversas formas, revelam significados mais amplos sobre os fenômenos a que se referem" (IBGE, 2012)

Particularmente no que diz respeito ao meio ambiente e à proposição de indicadores de sustentabilidade ambiental, as principais restrições dizem respeito à pouca disponibilidade e uniformidade de dados, dificultando abordagens mais completas e sistêmicas, principalmente relativo ao uso da água, erosão e perda de solo e desertificação (IBGE, 2012).

Como ferramenta de interação, facilita a comunicação entre tomadores de decisão, fazedores de políticas e a sociedade. Na esfera ambiental, um indicador ambiental pode ser entendido como:

[..] a representação de um conjunto de dados, informações e conhecimentos acerca de determinado fenômeno urbano/ambiental capaz de expressar e comunicar, de maneira simples e objetiva, as características essenciais (como ocorrência, magnitude e evolução, 
entre outros aspectos) e o significado (como os efeitos e a importância sócio-ambiental associado) desse fenômeno aos tomadores de decisão e à sociedade em geral (SEI, 2006, p.10).

Boa parte desses indicadores dá ideia da eficiência e efetividade de um sistema produtivo, tendo em vista a utilização dos recursos que the são disponíveis. Conforme a OCDE (2002), os indicadores podem expor aspectos do estado do meio ambiente, do funcionamento de sistemas ambientais e da integração de políticas ambientais a políticas setoriais ou macropolíticas e ainda favorecer a implementação de medidas indutoras da sustentabilidade. A OCDE, portanto, sugere a aplicação de indicadores e índices para a avaliação do funcionamento dos sistemas ambientais; integração das preocupações ambientais em políticas setoriais; contabilidade ambiental; avaliação do estado do ambiente, entre outros.

Desde a Rio-92, a partir das diretrizes do desenvolvimento sustentável, um conjunto de indicadores passa a ser proposto como forma de promoção e construção da sustentabilidade, através da Comissão para o Desenvolvimento Sustentável (CDS), e a última revisão (2006) desses indicadores aponta para 96 itens, envolvendo as dimensões ambiental, social, econômica e institucional.

A construção de sociedades sustentáveis aparece na Agenda 21 como responsabilidade do governo, empresas e sociedade, e a formulação de indicadores é condição fundamental para a construção de uma política de relacionamento entre o setor produtivo e o meio ambiente. Assim, a Agenda 21 preconiza que os países devam "desenvolver sistemas de monitoramento e avaliação dos avanços, em relação ao desenvolvimento sustentável, através do uso de indicadores que meçam as mudanças nas dimensões econômica, social e ambiental" (SEI, 2006, p.7).

$\mathrm{Na}$ perspectiva mais geral de incentivo à responsabilidade social, a já referida norma Social Accountability, SA 8000 (SAI, 1997) incorpora princípios da 
Declaração Universal dos Direitos Humanos e da Declaração Universal dos Direitos da Criança, estando baseada nas normas da Organização Internacional do Trabalho (OIT). Os critérios para certificação devem envolver: 1) ausência de trabalho infantil; 2) ausência de trabalho forçado; 3) saúde e segurança; 4) liberdade de associação e direito à negociação coletiva; 5) ausência de discriminação 6) ausência de práticas disciplinares; 7) sistema estruturado de controle e remuneração das horas de trabalho; 8) política de salários e 9) sistema de gestão. Desta forma, trata-se da incorporação dos princípios de sustentabilidade às práticas empresariais.

No campo da certificação, desenvolvida pelo ISEA (Institute for Social and Ethical Accountability), destaca-se a norma AA 1000, que se refere a um sistema de gerenciamento da responsabilidade social e ética de empresas, no qual se sobressai o diálogo com todas as partes interessadas ou impactadas pela atividade empresarial. Conforme Mueller (2003), a intenção é criar relacionamentos estáveis com stakeholders e, consequentemente, melhorar a responsabilidade e o desempenho ético da organização.

$\mathrm{Na}$ perspectiva de avaliação das práticas de responsabilidade social empresarial, o Instituto Ethos vem desenvolvendo, desde 1999, sua série de indicadores, revisada em 2006, em parceria com o SEBRAE, para gerar uma versão incorporável pelas micro e pequenas empresas. A versão completa aborda sete temas: 1) valores, transparência e governança; 2) público interno; 3) meio ambiente; 4) fornecedores; 5) consumidores e clientes; 6) comunidade; 7) governo e sociedade.

Sob o prisma ambiental, devem ser observados: responsabilidade com gerações futuras, envolvendo o compromisso com a melhoria da qualidade ambiental, além da educação e conscientização ambiental, e o gerenciamento do impacto ambiental, através do gerenciamento do impacto de suas atividades e do 
ciclo de vida de produtos, minimização de entradas e saídas de materiais e sustentabilidade da economia florestal (ETHOS, 2008).

As orientações ambientais do Instituto Ethos encontram-se em consonância com as principais recomendações de gestão ambiental das organizações internacionais e com os parâmetros ambientais gestados no DS. Neste sentido, a United Nations Development Organization - UNIDO propõe o conceito de Desenvolvimento Industrial Ecologicamente Sustentável (DIES), dizendo respeito às "modalidades de industrialização que promovem as vantagens econômicas e sociais das gerações presentes e futuras, sem comprometer os processos ecológicos básicos" (UNIDO, 1991).

Dentro da proposta do DIES, a UNIDO, juntamente com o PNUMA, desenvolve o conceito de produção mais limpa, entendida como a "aplicação contínua de uma estratégia preventiva integrada, envolvendo processos, produtos e serviços a fim de alcançar benefícios econômicos, sociais para a saúde humana e o meio ambiente" (BARBIERI, 2011, p. 126), abordagem que envolve práticas para minimizar o consumo de energia e matéria-prima e a geração de resíduos e emissões, dispondo para isso de estratégias de prevenção, redução, reuso e reciclagem.

Proposto pelo World Business Council for Sustainable Development (WBCSD) e OCDE, o modelo baseado na Ecoeficiência é um modelo de produção e consumo sustentável, a partir da ideia de redução de materiais e energia por unidade de produto ou serviço, ao mesmo tempo de contribuição para a melhoria da qualidade de vida da população (BARBIERI, 2011).

Conforme Barbieri (2011), destacam-se, ainda, o projeto para o meio ambiente que consiste em projetos de produtos e processos que considerem os impactos ambientais e o programa de Gestão da qualidade ambiental total 
(TQEM), que estende os princípios de gestão da qualidade às questões ambientais.

A partir das discussões mais pertinentes à questão ambiental, portanto, define-se, aqui, uma matriz que envolve as dimensões Compromisso com a melhoria da qualidade ambiental (CMQA), Educação e conscientização ambiental (ECAM), Gerenciamento dos impactos sobre o meio ambiente (GISMA), Minimização de entradas e saídas (MINIES), bem como o conjunto de indicadores que lhes caracterizam, sistematizados no quadro 2, que apresenta, adicionalmente, os graus de importância atribuídos aos mesmos pelo painel de especialistas, através do Método Delphi.

Quadro 2 - Matriz de dimensões e indicadores de promoção da RSA no segmento de cerâmica vermelha - A perspectiva ambiental

Compromisso com a melhoria da qualidade ambiental (CMQA) (4)

Implementação de programas/ações internas de melhoramento e proteção do meio ambiente (4) Participação em eventos e congressos que tratem do tema ambiental (2) Ações de parceria e cooperação com outros produtores para melhoria ambiental (3) A questão ambiental está presente no planejamento estratégico da empresa (4) Ao desenvolver um novo negócio a empresa leva em conta os danos ambientais que o mesmo pode causar (4)

Política explícita de não-utilização de materiais e insumos provenientes de exploração ilegal de recursos naturais (como madeira, animais etc.) (4)

Processos para mapeamento e melhoria da qualidade ambiental, como estudos de solo, jazidas, reflorestamento etc. (4)

Apoio a pesquisas para o desenvolvimento de tecnologias menos danosas ao meio ambiente (4)

Estabelecimento de metas relativas à utilização de matérias-primas e destinação de resíduos (4)

Existência de política ambiental (3)

Elaboração de indicadores internos de avaliação da performance ambiental (3)

Dada a existência de política ambiental, ela é de conhecimento de todos os empregados (4) Participação em programas de certificação, créditos de carbono etc. (3)

Participação em algum programa externo de avaliação de conduta ambiental (2)

Educação e conscientização ambiental (ECAM) (4)

Ações voltadas para a proteção ou qualidade do meio ambiente (3)

Campanhas de conscientização e educação ambiental dirigidas a familiares de empregados (4) 
Campanhas de conscientização e educação ambiental dirigidas a fornecedores (4)

Campanhas de conscientização e educação ambiental dirigidas a consumidores (3)

Campanhas de conscientização e educação ambiental dirigidas a comunidades (4)

Campanhas (apoia ou participa) de projetos educacionais em parceria com organizações não governamentais e ambientalistas (4)

Campanhas educativas regulares com seus empregados de incentivos sobre temas ambientais (4)

Campanhas periódicas internas junto a seus funcionários para incentivar a reciclagens (4)

Campanhas periódicas internas de redução do consumo de água e de energia (4)

Campanhas periódicas internas de educação para o consumo consciente (3)

Gerenciamento dos impactos sobre o meio ambiente (GISMA) (4)

Avaliação dos impactos de suas atividades e de seus produtos ou serviços sobre o meio ambiente (4)

Substituição de equipamentos e atualizações tecnológicas visando a diminuição de seus impactos ambientais (4)

Manutenções periódicas de equipamentos visando a diminuição de seus impactos ambientais (4)

Cumprimento das exigências legais no que tange às normas ambientais (4)

Atuação para correção de danos ambientais (4)

Informações aos consumidores e clientes sobre danos ambientais resultantes do uso e da destinação final dos seus produtos (3)

Discussão e apresentação com empregados dos impactos ambientais causados por seus produtos ou serviços (3)

Discussão e apresentação com consumidores e clientes dos impactos ambientais causados por seus produtos ou serviços (2)

Discussão e apresentação com fornecedores dos impactos ambientais causados por seus produtos ou serviços (4)

Discussão e apresentação com comunidades dos impactos ambientais causados por seus produtos ou serviços (3)

Uso sustentável da biodiversidade e restauração do habitat natural (4)

Adoção de medidas de reciclagem e reuso de perdas e peças defeituosas (4)

Compras de fornecedores que comprovadamente tenham boa conduta ambiental (4)

Minimização de entradas e saídas (MINIES) (3)

Utilização de fontes alternativas de energia e de matérias-primas nocivas ao meio ambiente(4)/Economia de gastos com energia elétrica(4)/Uso racional de água(4)/Medição e monitoramento periódico dos aspectos ambientais significativos relacionados ao consumo de recursos naturais e à produção de resíduos estabelecendo periodicamente novas metas(3)/Medidas para a redução da produção de resíduos (sólidos, líquidos, orgânicos etc.)(3)/Utilização de produtos advindos de atividades que não prejudiquem 0 meio ambiente(4)/Destinação de resíduos (sólidos, líquidos, orgânicos etc.) de forma a não agredir o meio ambiente(4)/Submissão de produtos acabados a ensaios mecânicos para controle da qualidade (3)

Fonte: Revisão de literatura e painel de especialistas. 
Relativo ao mercado de trabalho, reconhece-se que este possui uma dimensão social para além da econômica. Para Ramos (2007, p.7), pode se asseverar "que as ações relativas ao mercado de trabalho são fundamentais para promover a equidade e o bem-estar de uma sociedade", elementos cruciais para as propostas de desenvolvimento. Para a OIT (2009, p. 9):

[..] a superação de todas as formas de discriminação e a promoção de modalidades de crescimento que fomentem o desenvolvimento humano e gerem trabalho decente constituem requisitos determinantes para a redução da pobreza, a autonomia das mulheres, o fortalecimento da democracia e o cumprimento dos Objetivos do Desenvolvimento do Milênio.

A caracterização de trabalho decente pela OIT (2007, p.20) refere-se, portanto, ao:

[...] trabalho produtivo com remuneração justa, segurança no local do trabalho e proteção social, melhores perspectivas para o desenvolvimento pessoal e social, liberdade para que manifestem suas preocupações, organizem-se e participem da tomada de decisões que afetam suas vidas, assim como a igualdade de oportunidades e de tratamento para mulheres e homens.

Assim, a RSA aparece como princípio ético e de construção da cidadania e promoção do desenvolvimento sustentável. Ressalta-se que são históricas as assimetrias em padrões de desenvolvimento dentro de uma mesma região, ou entre os setores de determinada economia, numa fragmentação espacial e setorial que reforça as chamadas "ilhas de prosperidade", que por sua vez se refletem nas assimetrias das condições de trabalho e nas relativas especificidades de cada atividade. A própria intervenção em termos de políticas públicas obedece ao comando do capital, ao grau de articulação e oligopolização dos setores, transferindo em parte, para as empresas, a prerrogativa de implementação de políticas que valorizem o trabalho mais justo e para a sociedade o papel de exercer fortes demandas para o cumprimento de ações com vistas ao desenvolvimento integrado e humano. 
A perspectiva de um desenvolvimento socialmente justo coloca o trabalho, portanto, na esfera de promoção da responsabilidade socioambiental, devendo as organizações promover medidas que reforcem a satisfação do trabalho. Essa satisfação, conforme Veloso, Bosquetti e Limongi-França (2005), diz respeito: a) ao potencial humano, refletido na capacitação, motivação e desenvolvimento profissional e b) nos aspectos de saúde e segurança do trabalho, envolvendo os meios para neutralização de riscos nas condições de trabalho, através de prevenção, correção e reparação de aspectos humanos e ambientais.

Mais recentemente, o trabalho decente passa a ser utilizado no conjunto de Indicadores Ethos, no que se refere ao comprometimento da empresa frente ao seu público interno, mesmo que na perspectiva e visão dos empregadores.

O compromisso com o desenvolvimento profissional e empregabilidade, do padrão Ethos, remete que "cabe à empresa comprometer-se com o investimento na capacitação e desenvolvimento profissional de seus empregados, oferecendo apoio a projetos de geração de empregos e fortalecimento da empregabilidade para a comunidade com que se relaciona" (ETHOS, 2008). O trabalho decente, para o Ethos, considera, por conseguinte, a possibilidade de ascensão profissional; reconhecimento da performance profissional; participação na política, gestão e estratégia da empresa, entre outros.

Considerando o conjunto desses elementos, os indicadores propostos relativos à dimensão Compromisso Com a Melhoria do Ambiente do Trabalho (CMAT), bem como os respectivos graus de importância atribuídos aos mesmos, encontram-se dispostos no quadro 3.

Quadro 3 - Matriz de dimensões e indicadores de promoção da RSA no segmento de cerâmica vermelha - A perspectiva do trabalho 
Compromisso com a Melhoria do Ambiente do Trabalho (CMAT) (4)

Recebimento e manuseio adequado de materiais (4)

Acondicionamento adequado de argila e demais insumos (4)

Armazenamento do produto e de peças cruas em local delimitado, organizado, com piso uniforme e coberto (4)

Armazenamento adequado dos resíduos em depósitos fixos ou temporários, impermeabilizados e cobertos (4)

Otimização do layout (3)

Cuidados com a saúde, segurança e condições de trabalho (4)

Compromisso com o desenvolvimento profissional e a empregabilidade (3)

Política de remuneração, benefícios e carreira (4)

Diálogo e gestão participativa (3)/Cumprimento de exigências legais relativas ao trabalho (4) Ações para inibir o uso do trabalho infantil, inclusive em associação com outras organizações (4)

Atração e retenção de mão de obra especializada (4)

Formas de cooperação ou parcerias entre produtores/destes com centros de capacitação profissional, assistência técnica e instituto de ensino e pesquisa. (3)

Fonte: Revisão de literatura e painel de especialistas.

Quintas e Oliveira (1995) chamam atenção para a indissociabilidade entre meio natural e meio social, onde o ser social atua incessantemente sobre sua base natural de sustentação, sendo, por sua vez, progressivamente afetado por sua dinâmica. Para os autores, são as práticas do meio social que determinam a natureza dos problemas ambientais, considerados nessa prática, o processo de acumulação de capital e a divisão social do trabalho. A concepção de que a problemática ambiental diz respeito à relação sistêmica entre sociedade e natureza, portanto, implica que ampliemos as dimensões que representem práticas de responsabilidade socioambiental, com a inclusão de indicadores sociais e relativos ao trabalho.

Os indicadores sociais atuam na mensuração dos "avanços ou retrocessos nas condições de vida da população, direciona as prioridades sociais e aponta os erros e acertos das políticas públicas" (GIROTO et al., 2008, p. 7). É um instrumento operacional para monitoramento da realidade social, para fins de formulação e reformulação das políticas sociais. No campo organizacional, 
fornece as diretrizes para que empresas avaliem sua intervenção junto aos seus funcionários, comunidades ou sociedade em geral.

Ressalta-se que a inclusão da dimensão social impõe à empresa a compreensão das relações vitais que se estabelecem entre a mesma e as pessoas e comunidades. Pressupõe incorporar a noção de capital social e humano vinculados à empresa, o que remete a reflexões sobre as relações de confiança recíproca estabelecida entre a corporação e seus diversos stakeholders, imprescindíveis para a construção de relações de longo prazo. Significa trabalhar para a construção de uma governança corporativa compromissada com vários interlocutores, onde se estabeleçam: relações de confiança com as comunidades; iniciativas de treinamento e educação; segurança do produto; investimentos em saúde e segurança alimentar; espaços de diálogos com seus interlocutores, entre outros.

A matriz proposta para a caracterização da perspectiva social, com seu conjunto de indicadores e graus de importância atribuídos aos mesmos, segue disposta no quadro 4.

Quadro 4 - Matriz de dimensões e indicadores de promoção da RSA no segmento de cerâmica vermelha - A perspectiva social

Compromisso com a responsabilidade social (CRS) (3)

Participação em projetos sociais governamentais (2)

Envolvimento e financiamento de ações sociais - trabalhadores (4)

Envolvimento e financiamento de ações sociais - comunidades (4)

Ações práticas relativas a lazer, cultura e educação física (4)

Ações voltadas para a formação da cidadania (2)

Gerenciamento do impacto da empresa na comunidade de entorno (4)

Relações com organizações locais (2)

Fornecedores observam requisitos socioambientais (3)

Critérios de seleção e avaliação de fornecedores (3)

Estratégia de governança e transparência de sua gestão socioambiental (3)

Diálogo e engajamento das partes interessadas (3)

Compromisso com a não discriminação e promoção da equidade racial e de gênero (4)

Preocupação mais estrutural com 0 desenvolvimento local orienta ações relativas à estrutura produtiva e à gestão empresarial de forma geral (2)

Fonte: Revisão de literatura e painel de especialistas. 


\section{CONCLUSÕES}

A reflexão sobre a sustentabilidade do desenvolvimento impõe que os sistemas produtivos, especialmente os industriais, sejam pensados sob a ótica da sustentabilidade, cuja busca da eficiência e rentabilidade não comprometa os recursos disponíveis às gerações futuras. Neste contexto, a empresa assume um novo papel, devendo incorporar às suas ações princípios de responsabilidade socioambiental, transcendendo os objetivos econômicos e contribuindo para a construção de novas formas de relação entre sociedade e meio ambiente.

Relativo à RSA, o resgate da literatura especializada caminhou para a construção de um conceito ou imperativo de que cultura organizacional deva estar fundamentada em três grandes princípios: relação ética e transparente da empresa com todas as partes interessadas; compromisso com uma produção sustentável, refletido num ambiente ecologicamente equilibrado e socialmente justo, indo além das exigências e demandas legalmente constituídas e atuação em sintonia com o desenvolvimento sustentável. Ao se refletir, adicionalmente, sobre os avanços nos sistemas de avaliação ambiental, na integração e aperfeiçoamento das normas certificadoras como instrumento de gestão, constata-se o quão distante, principalmente naquilo que diz respeito às pequenas e médias empresas ou de menor capitalização, estão os princípios da RSA das práticas organizacionais em vigência na atualidade.

A revisão da literatura especializada sobre o setor de cerâmica vermelha tem constatado que ações empreendidas para a gestão ambiental com vistas à sustentabilidade de sistemas ecológicos, econômicos e sociais têm se mostrado ambíguas, fragmentadas e pouco capazes de responder à complexidade dos desafios colocados ao setor. Nesse sentido, espera-se, como ressalta Mendonça (2002, p. 6), que instrumentos como o proposto nesse trabalho, ao serem 


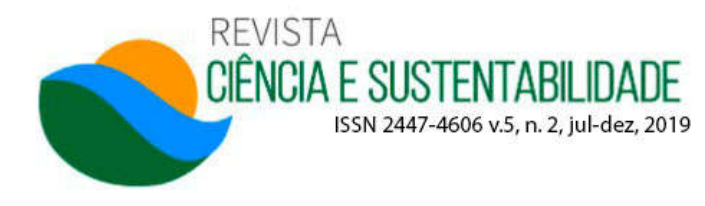

construídos de forma sistêmica, possam oferecer um ferramental técnico capaz de "oferecer às organizações uma possibilidade de aferir os impactos advindos de sua atuação, envolvendo um leque de atores sociais, com os quais elas se relacionam, direta e indiretamente, na realização diária de seus negócios".

\section{REFERÊNCIAS}

ABRAMOVAY, R. Responsabilidade socioambiental: as empresas no meio ambiente, o meio ambiente nas empresas. In: VEIGA, J. E. da (org.). Economia socioambiental. São Paulo: Ed. SENAC, 2009.

ADLER, M.; ZIGLIO E. Gazing into the Oracle: The Delphi Method and its Application to Social Policy and Public Health. London: Jessica Kingsley Publishers, 1996.

BARBIERI, José C. Gestão Ambiental Empresarial: Conceitos, Modelos e Instrumentos. São Paulo: Saraiva, 2011.

BEZERRA, Francisco D.; VIANA, Fernando Luiz E.; FARIA JR., Américo R. Diagnóstico do setor de cerâmica vermelha no Nordeste. Fortaleza: ETENE/Banco do Nordeste, 2001.

BLAU, Peter M.; SCOTT. W.R. Organizações formais. São Paulo: Atlas, 1977.

BORGER, Fernanda G. Responsabilidade social empresarial e sustentabilidade para a gestão empresarial. 2013. Disponível em: http://www3.ethos.org.br/cedoc/responsabilidade-social-empresarial-esustentabilidade-para-a-gestao-empresarial/\#.UozEosSkoTR. Acesso em: 21 set., 2013.

BOWEN, Howard R. Responsabilidades sociais do homem de negócios. Rio de Janeiro: Civilização Brasileira, 1957. 
CÂNDIDO et al. Método Delphi - uma ferramenta para uso em Microempresas de Base Tecnológica. Revista FAE, Curitiba, v.10, n.2, p.157-164, jul./dez., 2007.

DE CARLI, Paulo César; DELAMARO, Maurício C.; SALOMON, Valério A.P. Identificação e priorização dos fatores críticos de sucesso na implantação de fábrica digital. Produção, v. 20, n. 4, out./dez., p. 549-564, 2010.

ESPERON et al. Funciones y tareas asistenciales de enfermeria en los cuidados intensivos. Rev. Cub. Med. Int. Emerg. 3(4), p. 24-46, 2004.

ETHOS. Instituto Ethos de Empresas e Responsabilidade Social. Incentivando a gestão empresarial socialmente responsável. Meio Ambiente. 2013. Disponível em: http:/www3.ethos.org.br/conteudo/gestao-socialmenteresponsavel/meio-ambiente/\#.UozClcSkoTR. Acesso em: 17 out., 2013.

Ethos, 2008.

Indicadores Ethos de responsabilidade social. São Paulo: Instituto . Responsabilidade social das empresas: a contribuição das universidades. São Paulo: Peirópolis, v.II, 2003a.

FRIEDMAN, Milton. Capitalismo e liberdade. São Paulo: Abril Cultural, 1984. SKULMOSKI, G. J.; HARTMAN, F. T.; KRAHN, J. The Delphi Method for Graduate Research. Journal of Information Technology Education, v. 6, p. 122, 2007.

GIOVINAZZO, Renata A. Modelo de aplicação da metodologia Delphi pela internet: vantagens e ressalvas. Administração On Line. v.2, n. 2, abr./jun., FECAP, 2001.

GIROTO, Ana Paula S. et al. Indicadores sociais: um imperativo no cotidiano dos assistentes sociais atuantes no processo de gestão. Serviço Social em Revista. v.10, n.2, jan./jun., p.1-27, Uel, 2008.

INSTITUTO BRASILEIRO DE GEOGRAFIA E ESTATÍSTICA - IBGE. Indicadores de Desenvolvimento Sustentável: Brasil, 2012. 


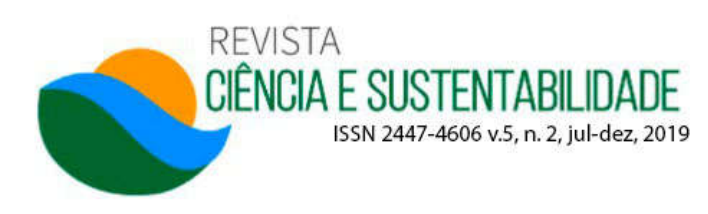

LINARD, Zoraia Úrsula S. de A. Impactos socioambientais causados pelas atividades da indústria de cerâmica vermelha do município de Crato-Ce. Dissertação de Mestrado. Programa de Pós-graduação em Desenvolvimento e Meio Ambiente. Universidade Federal do Ceará. Fortaleza, 2011.

MELO NETO, Francisco Paulo de; FROES, César. Gestão da responsabilidade social corporativa: o caso brasileiro. Rio de Janeiro: Qualitymark, 2001.

MENDONÇA, R. R. S. As dimensões da responsabilidade social: uma proposta de instrumento de avaliação. Dissertação (Mestrado em Sistemas de Gestão). Universidade Federal Fluminense. Rio de Janeiro, 2002.

MUELLER, Adriana. A utilização dos indicadores de Responsabilidade Social Corporativa e sua relação com os stakeholders. Dissertação (Mestrado em Engenharia de Produção). Programa de Pós-graduação em Engenharia de Produção. Universidade Federal de Santa Catarina, Florianópolis (SC), 2003.

ODELL, Henry R. What does social responsibility of business mean? Academy of Managemen. Boston, Mississippi, Academy of Management, p. 597601,1974 .

OLIVEIRA, Joelma de S.P.; COSTA, Maíra M.; WILLE, Marina F.de C. Introdução ao Método Delphi. Curitiba: Mundo Material, 2008.

ORGANIZAÇÃO DE COOPERAÇÃO E DESENVOLVIMENTO ECONÔMICO OCDE. Rumo a um desenvolvimento sustentável: indicadores ambientais. Tradução Ana Maria Teles, Salvador (Centro de Recursos Ambientais). Série Cadernos de referência ambiental; v.9, 2002. 244 p.

ORGANIZAÇÃO INTERNACIONAL DO TRABALHO-OIT. Trabalho e família: rumo a novas formas de conciliação com responsabilidade social. Brasília: OIT, 2009. 
Trabalho decente e juventude. América Latina. Resumo Executivo. Brasília: OIT, 2007.

PAULINO, Jorge. Método Delphi. Uma ferramenta de apoio ao planejamento das empresas. 2010. Disponível em: http://engenharianodiaadia.blogspot.com.br/2010/08/metodo-delphi-umaferramenta-de-apoio.html. Acesso em: 25 jul., 2014.

QUINTAS, J. S.; OLIVEIRA, M. J. G. A formação do Educador para atuar no processo de Gestão Ambiental. Brasília, IBAMA, 1995.

RAMOS, Lauro. O desempenho recente do mercado de trabalho brasileiro: tendências, fatos estilizados e padrões especiais. Texto para discussão, $\mathrm{n}$. 1255. Brasília: IPEA, 2007.

RICO, E. de M. A responsabilidade social empresarial do Estado. Uma aliança para o desenvolvimento sustentável. São Paulo em Perspectiva, 18(4), p.7382, 2004.

SÁFADI, C.M.Q. Delphi: um estudo sobre sua aceitação. In: V SEMEAD. 2001, São Paulo. Anais...São Paulo-SP: SEMEAD/FEA-USP, 2001.

SOUZA et al. Análise do impacto ambiental originado da queima de argila com resíduos industriais. In: $17^{\circ} \mathrm{CBECIMat}$ - Congresso Brasileiro de Engenharia e Ciência dos Materiais. 2006, Foz do Iguaçu, Anais..., Foz do Iguaçu/PR, Brasil, 2006.

SUPERINTENDÊNCIA DE ESTUDOS ECONÔMICOS E SOCIAIS DA BAHIA SEI. Indicadores de sustentabilidade ambiental. Salvador/BA: SEI, 2006.

TACHIZAWA, Takeshy. Gestão ambiental e responsabilidade social corporativa: estratégias de negócios focadas na realidade brasileira. 4. ed. São Paulo: Atlas, 2006. 427 p.

UNITED NATIONS INDUSTRIAL DEVELOPMENT ORGANIZATION - UNIDO. In: Proceedings of the conference on ecologically sustainable industrial development: Copenhague, Dinamarca, 14-18, out., 1991 




VELOSO, H. M.; BOSQUETTI, M. A.; LIMONGI-FRANÇA, A. C. A concepção gerencial dos programas e qualidade de vida no trabalho (QVT) no setor elétrico brasileiro. In: VII Seminário em Administração FEA-USP. 2005. São Paulo.

Anais... São Paulo, 2005. 